\title{
High-throughput approaches to investigate neutral lipid biosynthesis
}

This article was published in the following Dove Press journal:

International Journal of High Throughput Screening

30 March 2010

Number of times this article has been viewed

\section{Rodrigo MP Siloto \\ Randall J Weselake}

Agricultural Lipid Biotechnology Program, Department of Agricultural, Food and Nutritional Science, University of Alberta, Edmonton, Alberta, Canada
Correspondence: Randall J Weselake University of Alberta, Department of Agricultural, Food and Nutritional Science, 4-10 Ag/For Centre, Edmonton, $\mathrm{AB}$, Canada T6G 2P5

$\mathrm{Tel}+\mathrm{I} 780492440$ I

Fax +I 7804926739

Email randall.weselake@ualberta.ca
Abstract: Neutral lipids are ubiquitously found in nature, serving primarily as energy storage compounds. The ability to control the rate of neutral lipid bioassembly is of particular interest in numerous applications. For example, restriction of triacylglycerol and steryl ester synthesis in mammals could serve as adjuvant therapies against important diseases. In oilseeds, a boost in triacylglycerol accumulation would have a great impact in agriculture. Developing mechanisms to regulate neutral lipids synthesis requires rather specialized experimental designs where highthroughput screening approaches could be applied. Here we describe several enzyme targets that catalyze the bioassembly of neutral lipids, and potential applications for mechanisms that regulate their activity. We also describe different biochemical and cell-based assays to detect neutral lipid biosynthesis that are compatible with high-throughput formats. Several examples of established and prospective applications for these assays are discussed.

Keywords: neutral lipids, lipotoxicity, Nile red, scintillation proximity assay

\section{Introduction}

Experimental designs involving rapid analysis of large sets of samples are becoming increasingly popular in life sciences. High-throughput screening (HTS) is often used to describe a segment of drug discovery technologies where libraries of compounds are tested for an effect against a protein target. HTS techniques have been used also in different applications including directed evolution and inverse metabolic engineering. These techniques can be divided into two major categories: biochemical assays and cell-based assays. Biochemical assays are performed in miniaturized in vitro formats and have been used to detect and quantify the activity of a variety of different enzymes. ${ }^{1-4}$ In vitro reconstituted enzyme activity, however, does not always translate into an effect in vivo. Cell-based assays overcome this problem because the effect is measured directly in a live cell-context. This type of assay is becoming more frequently used $^{5}$ because it allows the screening of multiple targets in a pathway, highlighting compounds that can infiltrate cells and also providing indications of cytotoxicity. ${ }^{6}$ There are several examples of cell-based HTSs described in the literature. ${ }^{7-9}$ Both types of assays are becoming available to study the activity of enzymes that catalyze the synthesis of neutral lipids on a large scale. In this review we describe important targets related to the synthesis of neutral lipids and techniques that can be used in a high throughput manner. We discuss how these techniques can be used in specific HTS designs, with a broad range of pharmaceutical, agricultural, and biotechnological applications. 


\section{Targets and applications in neutral lipid research}

Neutral lipids are compounds of reduced carbon and can be divided into distinct groups based on their chemical structures: triacylglycerol (TAG), steryl ester (SE), wax ester (WE), and polyhydroxyalkanoate (PHA). These compounds typically function as a repository of energy that can be utilized in conditions of nutrient deprivation. Indeed, neutral lipids are very efficient forms of energy storage. For example, the energy of complete oxidation of long acyl chains is more than twice that of the energy derived from the same weight of carbohydrate or protein. These lipids are deposited into cytoplasmic lipid droplets ${ }^{10,11}$ without requiring water of solvation and thus having practically no effect on the osmolarity of the cytosol. Excessive accumulation of neutral lipids in mammals is generally not desired as it is associated with different pathologies. In contrast, in certain plants and fungi, increased production of these lipids is sought for their industrial applications.

\section{Triacylglycerol}

TAG is an acyl ester of glycerol found in virtually all eukaryotes and also in some prokaryotes. ${ }^{12-14}$ It functions not only as an energy reservoir but also as an inert deposit of fatty acids that can be used to build membranes. The last committed step of TAG biosynthesis is catalyzed by diacylglycerol acyltransferase (DGAT, EC 2.3.1.20) that utilizes $s n$-1, 2-diacylglycerol (DAG) and acyl-CoA substrates. Two distinct polypeptides, referred to as DGAT1 $1^{15,16}$ and DGAT2, ${ }^{17-19}$ have been identified in a variety of eukaryotes. Compelling evidences showed that DGAT1 and DGAT2 have distinct physiologic functions in mammals and plants. ${ }^{19-21}$ Another distinct DGAT, sometimes referred to as DGAT3, was identified in peanuts. ${ }^{22}$ TAG synthesis is also catalyzed by phospholipid:diacylglycerol acyltransferase (PDAT, EC 2.3.1.158) which uses phospholipid as an acyl donor and DAG as an acceptor. ${ }^{23,24}$ In addition there is biochemical evidence for another enzyme known as diacylglycerol transacylase that utilizes two molecules of DAG to form TAG.$^{25}$ These enzymes can be collectively named TAG-synthesizing enzymes.

In mammals, TAG is associated with a number of homeostatic processes, including absorption of dietary fatty acids, energy storage in muscle and adipose tissues, and milk fat production. ${ }^{26}$ Excessive accumulation of TAG contributes to obesity and hypertriglyceridemia that represent serious health care problems. Appropriate nutrition and regular exercise are the first choice to prevent these health problems. In certain cases, however, therapeutic approaches targeting appetite sup- pression, fat absorption, or rate of metabolism are used. More advanced generations of drugs, which control the biosynthesis of TAG by inhibiting relevant enzyme activities, have also been studied. ${ }^{27}$ Treatments with A-922500, an inhibitor of DGAT1, have been demonstrated to reduce serum TAG levels in hypertriglycemic animal models..$^{28} \mathrm{~A}$ compound of the pyrimidino-oxazine class of DGAT-1 inhibitors also shows effective body weight reduction in mice. ${ }^{29}$ These and other studies $^{30}$ suggest that small molecule inhibitors of DGAT have the potential to be used in the treatment of obesity and metabolic syndrome, underscoring the significance of an efficient and target-based HTS for DGAT activity.

TAG is the major component of vegetable oils that are commonly used in food preparation and also as a renewable feedstock for a number of industrial applications. Vegetable oils can serve as substitutes for petroleum-derived products in the production of different industrial fluids and lubricants. ${ }^{31}$ Plants can be modified by metabolic engineering to enhance the production of seed oil. The capacity of oilseeds to accumulate oil is of paramount importance, and several strategies to increase TAG content in seeds have been explored. ${ }^{32}$ Amongst these strategies is the overexpression of DGAT1 or DGAT2 in oilseeds which resulted in increases in seed oil accumulation. ${ }^{33,34}$ There is interest in increasing the activity of DGAT and other TAG-synthesizing enzymes in oilseeds and we are currently using a directed evolution approach on DGAT1 with this purpose. ${ }^{35}$

In addition to increasing oil accumulation in seeds, plant metabolic engineering has been also used in the production of specialty oils with superior industrial or nutritional value..$^{36,37}$ In this case, metabolic pathways leading to the synthesis of unusual fatty acids are transferred from the original organisms to crops with desirable agronomic features.$^{38}$ One of the bottlenecks frequently observed with this strategy is that nonnative fatty acids are not always efficiently incorporated into TAG. Selective TAG-synthesising enzymes that can utilize or not discriminate atypical substrates can create a metabolic pull into TAG, enhancing the accumulation of the desired fatty acids. ${ }^{39,40}$ Directed evolution has been used to modify the substrate selectivity of enzymes ${ }^{41}$ and requires specialized HTS methods. Several applications in metabolic engineering of oilseeds would benefit from TAG-synthesizing enzymes with increased selectivity to substrates containing a particular acyl chain.

\section{Steryl esters}

SE serves as a reserve of sterols that are involved in membrane stability and synthesis of hormones in mammals. 
The final step of SE formation is accomplished by two distinct enzyme reactions. The first one, catalyzed by acyl-coenzyme A:cholesterol acyltransferase (ACAT, EC 2.3.1.26), uses sterol and acyl-CoA as substrates. Two ACAT isoforms (ACAT1 and ACAT2) have been characterized in mammals and other eukaryotes. ${ }^{42,43}$ The second reaction is catalyzed by lecithin:cholesterol acyltransferase (LCAT, EC 2.3.1.43) which utilizes phospholipids as acyl donors. Similar to TAG, SE is stored in cytoplasmic lipid droplets as part of the lipid homeostasis. Excessive accumulation of SEs in macrophages leads to the formation of foam cells in arteries that are involved in the development of atherosclerosis. In addition, there are indications that ACAT1 is genetically linked with the risk of developing Alzheimer's disease. ${ }^{44,45}$

ACATs were envisaged as promising targets for the development of drugs to prevent atherosclerosis and hypercholesterolemia. Over the last two decades, pharmaceutical companies have devoted considerable effort to develop novel drugs based on ACAT inhibitors. ${ }^{46}$ Although some of these compounds, such as avasimibe and pactimibe, showed initial favorable results, they failed to reduce atherosclerotic lesions in clinical trials. ${ }^{47-50}$ It has been demonstrated, however, that inhibition of ACAT2 in the liver with antisense oligonucleotides protected against diet-induced hypercholesterolemia and SE deposition in the arteries of animal models, ${ }^{51}$ indicating that therapies with ACAT inhibitors are feasible. Similar to DGAT, screening of small compounds that inhibit ACAT activity requires a target-based HTS design. Previous frustrations on finding effective ACAT inhibitors in humans highlight the need for a specialized cell-based HTS of new drugs which might increase the chances of identifying effective compounds.

\section{Wax esters}

A WE is a neutral lipid composed of a long-chain fatty alcohol esterified with a fatty acid. WEs are widely found in nature, predominantly in the surface layer of plants and insects that protect against moisture and prevent desiccation. ${ }^{52}$ These lipids are also produced by mammalian meibomian and sebaceous glands and are involved in epidermal and ocular surface homeostasis, and also in the development of acne. ${ }^{53}$ WEs are synthesized by the catalytic action of acyl-CoA:wax alcohol acyltransferases (wax synthase, WS, EC 2.3.1.75). WS genes were first identified from jojoba. ${ }^{54}$ Subsequently, bifunctional enzymes with DGAT activity (WS/DGAT) were identified in petunia and Arabidopsis..$^{55,56}$
In mammals, two enzymes presenting WS activity belong to the DGAT2 multigene family. ${ }^{57}$

WEs have several industrial applications, including production of cosmetics, polishes, coatings, lubricants, and food-based products. ${ }^{58}$ Historically these lipids were first obtained from sperm whales which are now considered an endangered species. The current sources of WEs are jojoba seeds, leaves of tropical plants, and a variety of insects including honeybee. WEs can be also produced by hydrogenation of castor oil which contains fatty acids with secondary hydroxyl groups. Castor wax is a component of coating formulations for wood, leather, and rubber. Strategies to produce WEs in transgenic plants have been envisaged,${ }^{54}$ highlighting the importance of discovering novel WS genes. A functional genomics approach could be employed for the discovery of novel enzymes from unexplored plant and animal sources. For example, the plant species Copernicia prunifera (Brazilian carnauba wax) and Euphorbia antisyphilitica (Mexican candelilla wax) and the insect Ceroplastes ceriferus (Chinese wax) are important sources of wax that have not yet been explored at the genomic level. Of particular interest are WSs selective for specific substrates such as those containing secondary hydroxyl groups. Directed evolution of WSs could be used to modify the substrate selectivity of these enzymes. Such applications would require a HTS method for detecting and quantifying the activity of WS in large scale.

\section{Polyhydroxyalkanoates}

PHAs are polyesters produced by a wide variety of bacteria serving as a reserve of carbon and energy. These compounds can be sorted into different classes based on their monomer composition, and each of these classes has unique physical properties. PHAs are produced by the catalytic action of PHA synthases (EC 2.3.1.B2, 2.3.1.B3, or 2.3.1.B4) that catalyze the polymerization of hydroxyacyl-CoA precursors..$^{59}$ PHAs have material properties similar to petroleum-based plastics like polypropylene, representing an attractive source of plastics that can be produced using renewable materials and degraded by microorganisms, thus minimizing the waste volume. ${ }^{60}$ Because of high costs of fermentation-based processes and competition with well-established production of fossil fuel-based plastics, PHAs have been alternatively produced in plants through metabolic engineering. ${ }^{61,62}$ Directed evolution and protein engineering approaches have been used to increase the activity and modify the substrate selectivity of PHA synthases. ${ }^{63-65}$ Both applications make use of specific HTS methodologies that have been established. 


\section{Biochemical assays: scintillation proximity assays}

Standard methods to quantify the activity of enzymes involved in the assembly of neutral lipids require laborious assays ${ }^{66}$ Neutral lipids are hydrophobic molecules and their isolation entails time-consuming techniques involving extraction with organic solvents and/or thin layer chromatography. With the exception of DGAT3 from peanuts, most enzymes involved in neutral lipid synthesis are associated with membranes. ${ }^{67}$ In order to obtain reliable measurements and higher specific activity values, microsomal fractions are often used as a source of these enzymes in in vitro assays. Membranes must be isolated with ultracentrifugation, further decreasing the throughput of the assay. In addition, the activity of enzymes that synthesize neutral lipids is notoriously low, requiring the use of radiolabelled substrates and scintillation measurement for appropriate detection of in vitro synthesized lipids. These factors hamper the use of conventional techniques in high throughput formats. To address this problem, a homogeneous scintillation proximity assay (SPA) was developed to quantify the activity of DGAT in vitro. ${ }^{6}$

SPAs rely on the close association between a high energy $\beta$-particle radioisotope such as tritium and a beadcontaining scintillant which emits light upon stimulation. When a radioisotope decays, the $\beta$-particle has a short transferring path length and the energy easily dissipates in the aqueous solution without being detected. When in close proximity to the bead, the energy of the $\beta$-particle is transferred to the scintillant, resulting in light emission that can be detected by photo multiplier tube-based liquid scintillation counters or other charge-coupled device imaging systems. ${ }^{69}$ This assay has been routinely used to detect and quantify the activity of a variety of enzymes and is well documented in the literature. ${ }^{70-73}$ DGAT SPA was developed using DAG and tritium-labelled acyl-CoA as substrates. The radiolabelled TAG product is bound to SPA beads, and the close proximity of tritium to the beads generates a signal that can be easily detected while the excess of tritium-labelled acyl-CoA is quenched by bovine serum albumin, remaining undetected. ${ }^{68}$ The signal can be detected in the same reaction container, avoiding further processing, and it is stable for at least 20 hours, making the assay amenable for multi-well plate formats. It is important to consider that the specificity of the detection depends on the affinity of the product for the bead as well as a reliable quenching mechanism. The DGAT SPA was evaluated with different types of beads and the yttrium oxide (YOX) polylysine and the yttrium silicate (YS) polylysine beads resulted in the best signal/background ratios. YOX and YS beads also presented affinity for DAG and, therefore, the same assay format can detect the activity of MGAT which uses monoacylglycerol and acyl-CoA to form DAG. ${ }^{68} \mathrm{It}$ is plausible to assume that extension of this method to other enzymes synthesizing TAG and other neutral lipids (such as ACATs, WSs, and PHA synthases) will be possible with technical adjustments to optimize the interaction between the synthesized lipid and the bead.

DGAT inhibition experiments confirmed a good correlation between $\mathrm{IC}_{50}$ values obtained by standard methods and by SPA methods, showing that this technology can be applied as a HTS of target-specific DGAT inhibitors for the development of novel drugs. ${ }^{74}$ In this case, the HTS design would consist of a membrane preparation containing a single recombinant DGAT tested against libraries of small molecular weight compounds. DGAT SPA can also facilitate the study of kinetic parameters of DGATs and the development of substrate selectivity assays in large scale. These types of experiments have not been extensively explored because of the technical difficulties previously discussed.

\section{Cell-based assays: lipotoxicity as a basis for positive selection}

Virtually any cell has the ability to synthesize neutral lipids as a buffering mechanism to regulate the level of intracellular fatty acids but, among mammalian cells, only adipocytes are specialized for storing considerable amounts of fat. Nonadipose tissues have limited capacity for TAG synthesis and when this biochemical pathway is saturated, it results in accumulation of important signalling molecules such as DAG and sphingolipids, leading to cellular dysfunction. For instance, saturated fatty acids are precursors for ceramides, a sphingolipid that induces apoptosis. ${ }^{75}$ This phenomenon, known as lipotoxicity, plays an important role in different pathologies, ${ }^{76,77}$ and has been associated with lack of DGAT activity in animal cells. For example, in Drosophila DGAT (-/-) knockout, egg chambers contain reduced levels of neutral lipids and undergo premature cell death. ${ }^{78}$ Supplementation of wild-type Chinese hamster ovary cells with exogenous oleic acid is well tolerated and leads to TAG synthesis, but causes lipotoxicity in DGAT (-/-) knockouts. ${ }^{79}$ Induction of lipotoxic cardiomyopathy in mice is prevented by expression of DGAT1 in the heart, reducing the levels of DAG, ceramide, and free fatty acids, and arguably improving heart function. ${ }^{80}$ As with animal cells, lipotoxicity has also been observed in yeast. The budding yeast Sac-

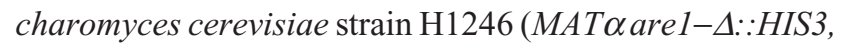


are $2-\Delta:: L E U 2$, dga1- $\triangle::$ KanMX4, lro1- $\triangle:: T R P 1$ ADE2) contains disruptions within four genes that contribute to the synthesis of neutral lipids (dgal, lro 1, are, and are 2). ${ }^{81}$ While dgal and lrol (encoding a DGAT2 and PDAT, respectively) are responsible for most of TAG synthesis, are1 and are 2 catalyze the synthesis of SEs, contributing minimally to TAG accumulation. Yeast has a natural ability to internalize exogenous fatty acids, ${ }^{82,83}$ and although $\mathrm{H} 1246$ is viable under normal growth conditions, recent studies demonstrated that supplementation of oleic acid induces lipotoxicity in this strain, resulting in cell death. ${ }^{84-86}$ This phenotype can be effectively elicited by mono- and polyunsaturated fatty acids. Curiously, supplementation of palmitic acid could reverse the effect of oleic acid, indicating that imbalances of fatty acid composition in the membrane play an important role in lipotoxicity. Characterization of the cellular and genetic events following fatty acid supplementation revealed the mechanisms involved in lipotoxicity. These mechanisms are initiated by generalized transcriptional changes in reaction to stress, followed by production of reactive species of oxygen, membrane proliferation, and induction of unfolded protein response, and culminated in cell death. ${ }^{84,85}$ Genetic screens with different acyltransferase mutants identified diacylglycerol kinase (encoded by $d g k l$ ) and phosphatidylethanolamine $\mathrm{N}$-methyltransferase (encoded by opi3) as modulators of lipotoxicity. ${ }^{84} \mathrm{~A}$ similar phenomenon was found in the fission yeast Schizosaccharomyces pombe double knockout (DKO)

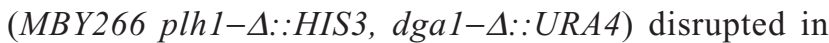
plh1 and dgal that encode PDAT and DGAT2, respectively. DKO presents a significant decrease in TAG accumulation and decreased viability when the cells enter the stationary growth phase. ${ }^{87}$

The lipotoxic phenotype in H1246 induced by oleic acid was reversed with the expression of DGAT1, DGAT2 or PDAT from different organisms ${ }^{8486}$ and was used to select clones displaying DGAT activity in a library of mutagenized DGAT $1,{ }^{35}$ demonstrating the utility of this phenotype as a positive selection system. This activity-based selection procedure could be used to screen cDNA libraries and identify novel enzymes using functional genomics approaches or to select active clones in directed evolution projects. An activity-based selection system is pivotal in the complete screening of larger libraries (ie, $>100,000$ events) that otherwise could be challenging to analyze completely. Activitybased screenings have been used in directed evolution of many enzymes including endopeptidases, xylose reductase, and cytochrome $\mathrm{P} 450$ propane monooxygenase. ${ }^{88-92}$ The reversion of lipotoxicity could be possibly used for other enzymes such as WSs. As previously described, these enzymes also utilize acyl-CoA and therefore may be used to detoxify supplemented fatty acids to H1246.

Although this activity-based screening enhances dramatically the capability of HTS strategies, it lacks a quantitative dimension. Moreover, it was also documented that expression of other genes, such as diacylglycerol kinase, can reverse fatty acid induced lipotoxicity, which could mask the effects of neutral lipid biosynthesis in functional genomics attempts. ${ }^{84,87}$ Therefore, high throughput methods enabling detection of neutral lipids are still needed to complement this activity-based selection.

\section{Cell-based assays: in situ fluorescent quantification of neutral lipids}

Fluorescence-based assays are widely applied in life sciences to detect proteins, compounds, interactions, and functions in live organisms. A plethora of fluorophores that excite and emit over a broad spectrum of wavelengths allows simultaneous monitoring of multiple events, making fluorescence-based assays suited to high throughput experiments. Nile red is a fluorescent dye commonly used to stain neutral lipid particles. It exhibits differential fluorescence properties depending on the type of lipid with which it associates. ${ }^{93}$ A yellow fluorescence is observed at excitation $460 \mathrm{~nm}$ and emission 505-555 $\mathrm{nm}$ when Nile red associates with neutral lipids. Red fluorescence is produced with excitation $540 \mathrm{~nm}$ and emission $>590 \mathrm{~nm}$ when it is associated with polar lipids. ${ }^{94}$ Interaction with PHAs indicated a maximum excitation between 540 to $560 \mathrm{~nm}$ and emission between 570 to $605 \mathrm{~nm} .{ }^{95}$ Nile red is quenched in water and moves freely across cellular membranes making it possible to stain living cells with a single procedure, eliminating the need for sample preparation or wash. These characteristics make this dye useful as an indicator of neutral lipid content in high throughput assays.

Nile red has been extensively used to identify PHAs in bacteria using flow cytometry techniques. ${ }^{96-99}$ The combination of Nile red staining and flow cytometry is of special interest because it allows the isolation of subpopulations from a cell culture exhibiting a desired phenotype of neutral lipids. Direct supplementation of Nile red in the solid medium allows visualization of PHA in bacterial colonies as a qualitative assay, ${ }^{100}$ and this technique was used in the HTS for directed evolution of PHA synthase. ${ }^{101}$ The HTS consisted of a primary semiquantitative screening of bacterial colonies in solid medium containing Nile red, followed by secondary assays based on liquid and gas chromatography. Of 8337 colonies 
evaluated on the primary screen, only 300 were subjected to secondary assays, highlighting the significance of the Nile red assay. Two mutants of highly active PHA synthases developed with this method were later tested in plant recombinant systems, showing an 8-10-fold increase in PHA accumulation compared with the wild-type enzyme. ${ }^{101}$

Although Nile red can infiltrate most cells and tissues, permeation in live bacteria is only partially efficient, often requiring fixing steps to improve cell permeability, which decreases the viability of the cells after flow cytometry sorting. Adaptation of a sucrose shock permeation treatment allowed Nile red to enter the cells and provided reliable quantification of poly-3-hydroxybutyrate (PHB) in Escherichia coli while maintaining satisfactory cell viability. ${ }^{102}$ Nile red staining of PHAs was used in an inverse metabolic engineering approach to identify high PHB strains of Synechocystis PCC 6803, a freshwater cyanobacterium. ${ }^{103}$ Screening of a library containing 10,000 gene disruptions in Synechocystis using fluorescence-activated cell sorting allowed the identification of two knockouts that resulted in significant increases in PHB accumulation.

In eukaryotes, Nile red was used to screen marine unicellular organisms using flow cytometry ${ }^{104,105}$ or conventional spectrofluorimetry. ${ }^{106}$ In both cases, the Nile red assay showed good correlation between the fluorescence signal, red/yellow ratio, and the lipid content measured by gravimetry, highlighting the value of the method in the rapid characterization of microalgae lipid composition. A high throughput-compatible assay was also demonstrated in vertebrates for the screening of small molecules or genes regulating fat metabolism. This model was based on concomitant small molecule treatment and Nile red feeding on zebrafish larvae for several days followed by microscopic analysis. ${ }^{107}$ Nile red was also used to determine the activity of recombinant DGATs expressed

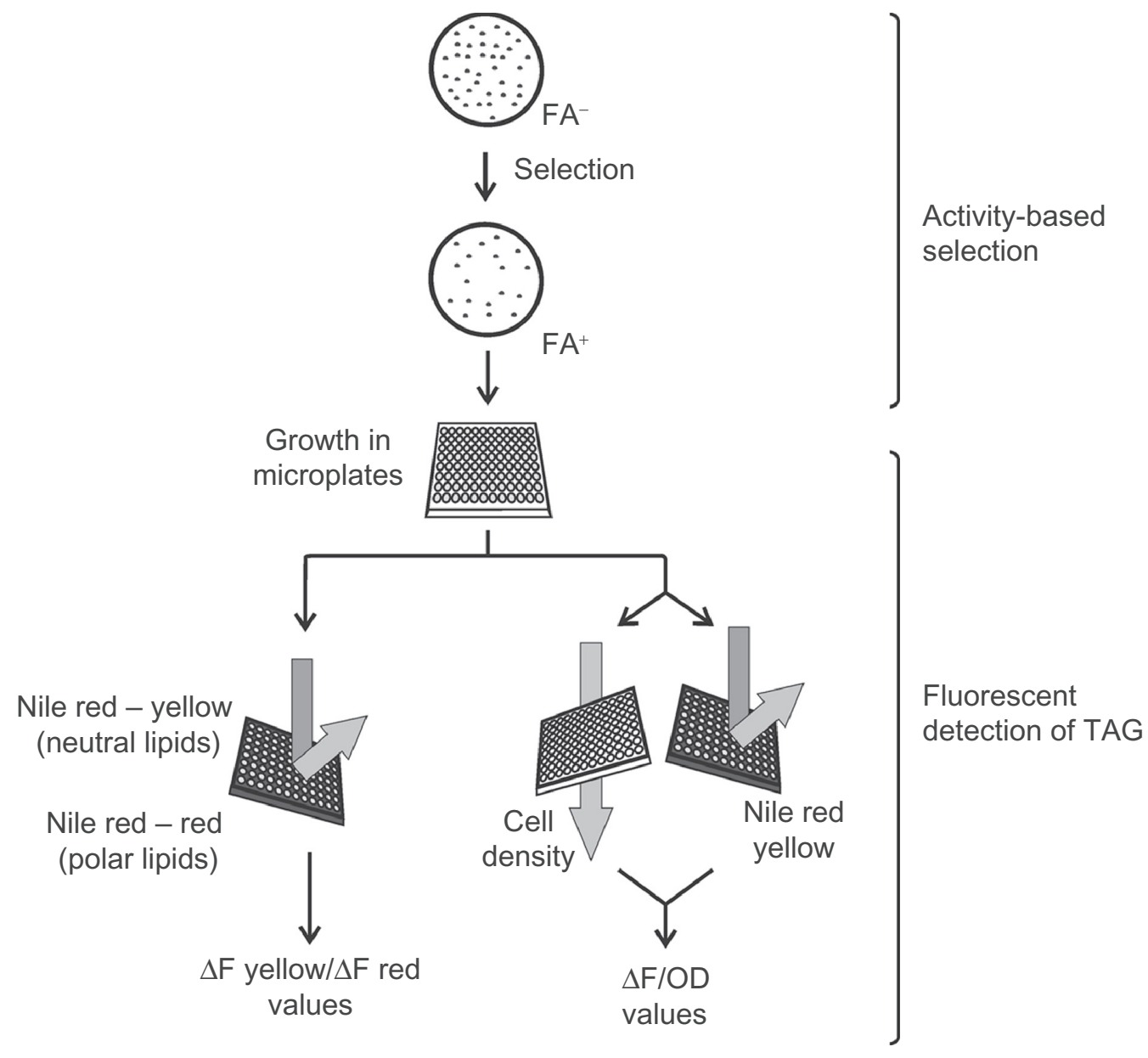

Figure I Scheme of a HTS system that can be used for directed evolution of DGATs. ${ }^{35}$ Recombinant yeast HI 246 cells expressing active DGATs are selected by inducing lipitoxicity in medium containing oleic acid. The selected yeast colonies are inoculated in 96 -well plates and cultivated to the stationary growth phase. Nile red fluorescence assay is conducted to measure the accumulation of TAG. The fluorescence values can be normalized by measuring the cell density $\left(\mathrm{OD}_{600}\right)$ where cell cultures are scored based on fluorescence as a function of $\mathrm{OD}_{600}(\Delta \mathrm{F} / \mathrm{OD})$. Alternatively fluorescence values can be also normalized by the red fluorescence where cell cultures are scored based on the amount of neutral lipids as a function of polar lipids ( $\Delta \mathrm{F}$ yellow/ $\Delta \mathrm{F}$ red).

Abbreviations: DGATs, diacylglycerol acyltransferases; HTS, high throughput screening;TAG, triacylglycerol. 
in S. cerevisiae strain H1246, showing a positive correlation between enzyme activity and the fluorescence measurement. ${ }^{86}$ Because H1246 lacks endogenous neutral lipids, a single protein target can be assessed, presenting a great advantage for study of the activity of these enzymes in a eukaryotic expression system. The combination of the lipotoxicity-based selection and Nile red assay in the H1246 strain is useful for a directed evolution approach. A flow diagram illustrating a HTS used in directed evolution of DGAT ${ }^{35}$ is shown in Figure 1. The expression in yeast strain H1246 also has the potential to identify modulators of enzyme activity which could be small molecular weight inhibitory compounds with potential therapeutic properties.

\section{Perspectives in neutral lipid HTS}

In this review we described an array of methods that can be used in HTS of enzymes involved in the synthesis of neutral lipids. It will be worthwhile to explore variations of these assays in different conditions and combinations. Establishing lipotoxicity-based selection in other organisms would greatly benefit cell-based assays. For example, reversion of the lipotoxic phenotype with TAG-synthesizing enzymes in $S$. pombe DKO cells ${ }^{87}$ should be assessed. In addition, the use of mammalian cells in drug discovery research might increase the rate of success for the development of novel therapies. It would be also helpful to establish a selection system for WSs by supplementing H1246 or DKO cells with fatty acids and fatty alcohols concomitantly. The development of novel cell-based assays could also be used to increase the performance of recombinant enzymes in the host organisms. For example, plant cell expression systems could be used to increase the adaptation of prokaryotic PHA synthases to the eukaryotic environment using directed evolution. Nile red assays are clearly the method of choice for in situ detection of neutral lipids in HTS. Incorporation of the red/yellow fluorescence ratio to distinguish different classes of lipids in the same sample would increase the quality of the assay. Finally, the use of the scintillation proximity assay will facilitate the characterization of kinetic parameters and substrate selectivity of novel enzyme variants generated by directed evolution.

\section{Acknowledgments}

We are grateful to AVAC Ltd, the Natural Sciences and Engineering Research Council of Canada, and the Canada Research Chairs Program for supporting our research on directed evolution of triacylglycerol-synthesizing enzymes. We also thank C Snyder for reviewing the manuscript.

\section{Disclosures}

The authors report no conflict of interest in this work.

\section{References}

1. Burns S, Travers J, Collins I, et al. Identification of small-molecule inhibitors of protein kinase B (PKB/AKT) in an AlphaScreenTM highthroughput screen. J Biomol Screen. 2006;11(7):822-827.

2. Sudo K, Yamaji K, Kawamura K, et al. High-throughput screening of low molecular weight NS3-NS4A protease inhibitors using a fluorescence resonance energy transfer substrate. Antivir Chem Chemother. 2005;16(6):385-392.

3. Swaney S, McCroskey M, Shinabarger D, Wang Z, Turner BA, Parker CN. Characterization of a high-throughput screening assay for inhibitors of elongation factor P and ribosomal peptidyl transferase activity. J Biomol Screen. 2006;11(7):736-742.

4. Kenny CH, Ding W, Kelleher K, et al. Development of a fluorescence polarization assay to screen for inhibitors of the FtsZ/ZipA interaction. Anal Biochem. 2003;323(2):224-233.

5. Fox S, Farr-Jones S, Sopchak L, et al. High-throughput screening: Update on practices and success. J Biomol Screen. 2006;11(7): 864-869.

6. Clemons PA. Complex phenotypic assays in high-throughput screening. Curr Opin Chem Biol. 2004;8(3):334-338.

7. Beck V, Pfitscher A, Jungbauer A. GFP-reporter for a high throughput assay to monitor estrogenic compounds. J Biochem Biophys Methods. 2005;64(1):19-37.

8. Yarrow JC, Totsukawa G, Charras GT, Mitchison TJ. Screening for cell migration inhibitors via automated microscopy reveals a Rho-kinase inhibitor. Chem Biol. 2005;12(3):385-395.

9. Eggert US, Kiger AA, Richter C, et al. Parallel chemical genetic and genome-wide RNAi screens identify cytokinesis inhibitors and targets. PLoS Biol. 2004;2(12):1235-1243.

10. Farese RV Jr, Walther TC. Lipid droplets finally get a little R-E-S-P-EC-T. Cell. 2009;139(5):855-860.

11. Czabany T, Wagner A, Zweytick D, et al. Structural and biochemical properties of lipid particles from the yeast Saccharomyces cerevisiae. J Biol Chem. 2008;283(25):17065-17074.

12. Farese RV, Cases S, Smith SJ. Triglyceride synthesis: Insights from the cloning of diacylglycerol acyltransferase. Curr Opin Lipidol. 2000;11(3):229-234.

13. Weselake R. Biochemistry and biotechnology of TAG accumulation in plants. In: Kuo TM, Gardner HW, editors. Lipid Biotechnology. New York, NY: Marcel Dekker; 2002:27-56.

14. Alvarez HM, Steinbuchel A. Triacylglycerols in prokaryotic microorganisms. Appl Microbiol Biotechnol. 2002;60(4):367-376.

15. Cases S, Smith SJ, Zheng YW, et al. Identification of a gene encoding an acyl CoA: Diacylglycerol acyltransferase, a key enzyme in triacylglycerol synthesis. Proc Natl Acad Sci U S A. 1998;95(22):13018-13023.

16. Hobbs DH, Lu CF, Hills MJ. Cloning of a cDNA encoding diacylglycerol acyltransferase from Arabidopsis thaliana and its functional expression. FEBS Lett. 1999;452(3):145-149.

17. Lardizabal KD, Mai JT, Wagner NW, Wyrick A, Voelker T, Hawkins DJ. DGAT2 is a new diacylglycerol acyltransferase gene family - Purification, cloning, and expression in insect cells of two polypeptides from Mortierella ramanniana with diacylglycerol acyltransferase activity. $J$ Biol Chem. 2001;276(42):38862-38869.

18. Cases S, Stone SJ, Zhou P, et al. Cloning of DGAT2, a second mammalian diacylglycerol acyltransferase, and related family members. J Biol Chem. 2001;276(42):38870-38876.

19. Shockey JM, Gidda SK, Chapital DC, et al. Tung tree DGAT1 and DGAT2 have nonredundant functions in triacylglycerol biosynthesis and are localized to different subdomains of the endoplasmic reticulum. Plant Cell. 2006;18(9):2294-2313.

20. Smith SJ, Cases S, Jensen DR, et al. Obesity resistance and multiple mechanisms of triglyceride synthesis in mice lacking Dgat. Nat Genet. 2000;25(1):87-90. 
21. Stone SJ, Myers HM, Watkins SM, et al. Lipopenia and skin barrier abnormalities in DGAT2-deficient mice. J Biol Chem. 2004;279(12):11767-11776.

22. Saha S, Enugutti B, Rajakumari S, Rajasekharan R. Cytosolic triacylglycerol biosynthetic pathway in oilseeds. Molecular cloning and expression of peanut cytosolic diacylglycerol acyltransferase. Plant Physiol. 2006;141(4):1533-1543.

23. Dahlquist A, Stahl U, Lenman M, et al. Phospholipid:diacylglycerol acyltransferase: An enzyme that catalyzes the acyl-CoA-independent formation of triacylglycerol in yeast and plants. Proc Natl Acad Sci U S A. 2000;97(12):6487-6492.

24. Stahl U, Carlsson AS, Lenman M, et al. Cloning and functional characterization of a phospholipid:diacylglycerol acyltransferase from Arabidopsis. Plant Physiol. 2004;135(3):1324-1335.

25. Lehner R, Kuksis A. Triacylglycerol synthesis by an sn-1,2(2,3)diacylglycerol transacylase from rat intestinal microsomes. J Biol Chem. 1993;268(12):8781-8786.

26. Farese RV Jr, Cases S, Smith SJ. Triglyceride synthesis: Insights from the cloning of diacylglycerol acyltransferase. Curr Opin Lipidol. 2000;11(3):229-234.

27. Tomoda H, Omura S. Potential therapeutics for obesity and atherosclerosis: Inhibitors of neutral lipid metabolism from microorganisms. Pharmacol Ther. 2007;115(3):375-389.

28. King AJ, Segreti JA, Larson KJ, et al. Diacylglycerol acyltransferase 1 inhibition lowers serum triglycerides in the Zucker fatty rat and the hyperlipidemic hamster. J Pharmacol Exp Ther. 2009;330(2): 526-531.

29. Birch AM, Birtles S, Buckett LK, et al. Discovery of a potent, selective, and orally efficacious pyrimidinooxazinyl bicyclooctaneacetic acid diacylglycerol acyltransferase-1 inhibitor. J Med Chem. 2009;52(6): $1558-1568$.

30. Fox BM, Furukawa N, Hao X, et al; inventors; Japan Tobacco Inc., assignee. Fused bicyclic nitrogen-containing heterocycles. PCT/ US2003/037574. 2003 Nov 21.

31. Metzger JO, Bornscheuer U. Lipids as renewable resources: Current state of chemical and biotechnological conversion and diversification. Appl Microbiol Biotechnol. 2006;71(1):13-22.

32. Weselake RJ, Taylor DC, Rahman MH, et al. Increasing the flow of carbon into seed oil. Biotechnol Adv. 2009;27(6):866-878.

33. Lardizabal K, Effertz R, Levering C, et al. Expression of Umbelopsis ramanniana DGAT2A in seed increases oil in soybean. Plant Physiol. 2008;148(1):89-96.

34. Weselake RJ, Shah S, Tang MG, et al. Metabolic control analysis is helpful for informed genetic manipulation of oilseed rape (Brassica napus) to increase seed oil content. $J$ Exp Bot. 2008;59(13):3543-3549.

35. Siloto RM, Truksa M, Brownfield D, Good AG, Weselake RJ. Directed evolution of acyl-CoA:diacylglycerol acyltransferase: Development and characterization of Brassica napus DGAT1 mutagenized libraries. Plant Physiol Biochem. 2009;47(6):456-461.

36. Jaworski J, Cahoon EB. Industrial oils from transgenic plants. Curr Opin Plant Biol. 2003;6(2):178-184.

37. Cahoon EB, Shockey JM, Dietrich CR, Gidda SK, Mullen RT, Dyer JM. Engineering oilseeds for sustainable production of industrial and nutritional feedstocks: Solving bottlenecks in fatty acid flux. Curr Opin Plant Biol. 2007;10(3):236-244.

38. Wu GH, Truksa M, Datla N, et al. Stepwise engineering to produce high yields of very long-chain polyunsaturated fatty acids in plants. Nat Biotechnol. 2005;23(8):1013-1017.

39. Burgal J, Shockey J, Lu CF, et al. Metabolic engineering of hydroxy fatty acid production in plants: RcDGAT2 drives dramatic increases in ricinoleate levels in seed oil. Plant Biotechnol J. 2008;6(8):819-831.

40. Yu KS, McCracken CT, Li RZ, Hildebrand DF. Diacylglycerol acyltransferases from Vernonia and Stokesia prefer substrates with vernolic acid. Lipids. 2006;41(6):557-566.

41. Farinas ET, Bulter T, Arnold FH. Directed enzyme evolution. Curr Opin Biotechnol. 2001;12(6):545-551.
42. Chang CCY, Huh HY, Cadigan KM, Chang TY. Molecular-cloning and functional expression of human acyl-coenzyme-a cholesterol acyltransferase Cdna in mutant Chinese-hamster ovary cells. $J$ Biol Chem. 1993;268(28):20747-20755.

43. Oelkers P, Behari A, Cromley D, Billheimer JT, Sturley SL. Characterization of two human genes encoding acyl coenzyme A:cholesterol acyltransferase-related enzymes. J Biol Chem. 1998;273(41): 26765-26771.

44. Bertram L, McQueen MB, Mullin K, Blacker D, Tanzi RE. Systematic meta-analyses of Alzheimer disease genetic association studies: the AlzGene database. Nat Genet. 2007;39(1):17-23.

45. Wollmer MA, Streffer JR, Tsolaki M, et al. Genetic association of acyl-coenzyme A:cholesterol acyltransferase with cerebrospinal fluid cholesterol levels, brain amyloid load, and risk for Alzheimer's disease. Mol Psychiatry. 2003;8(6):635-638.

46. Giovannoni MP, Piaz VD, Vergelli C, Barlocco D. Selective ACAT inhibitors as promising antihyperlipidemic, antiathero-sclerotic and anti-Alzheimer drugs. Mini Rev Med Chem. 2003;3(6):576-584.

47. Nissen SE, Tuzcu EM, Brewer HB, et al. Effect of ACAT inhibition on the progression of coronary atherosclerosis. $N$ Engl J Med. 2006;354(12):1253-1263.

48. Tardif JC, Gregoire J, L'Allier PL, et al. Effects of the acyl coenzyme A: cholesterol acyltransferase inhibitor avasimibe on human atherosclerotic lesions. Circulation. 2004;110(21):3372-3377.

49. Insull W Jr, Koren M, Davignon J, et al. Efficacy and short-term safety of a new ACAT inhibitor, avasimibe, on lipids, lipoproteins, and apolipoproteins, in patients with combined hyperlipidemia. Atherosclerosis. 2001;157(1):137-144.

50. Farese RV. The nine lives of ACAT inhibitors. Arterioscler Thromb Vasc Biol. 2006;26(8):1684-1686.

51. Bell TA, Brown JM, Graham MJ, Lemonidis KA, Crooke RM, Rudel LL. Liver-specific inhibition of acyl-coenzyme A:cholesterol acyltransferase 2 with antisense oligonucleotides limits atherosclerosis development in apolipoprotein B100-only low-density lipoprotein receptor(-/-) mice. Arterioscler Thromb Vasc Biol. 2006;26(8): 1814-1820.

52. Kunst L, Samuels AL. Biosynthesis and secretion of plant cuticular wax. Prog Lipid Res. 2003;42(1):51-80.

53. Smith KR, Thiboutot DM. Thematic review series: Skin lipids. Sebaceous gland lipids: Friend or foe? J Lipid Res. 2008;49(2): 271-281.

54. Lardizabal KD, Metz JG, Sakamoto T, Hutton WC, Pollard MR, Lassner MW. Purification of a jojoba embryo wax synthase, cloning of its cDNA, and production of high levels of wax in seeds of transgenic Arabidopsis. Plant Physiol. 2000;122(3):645-655.

55. King A, Nam JW, Han J, Hilliard J, Jaworski JG. Cuticular wax biosynthesis in petunia petals: Cloning and characterization of an alcohol-acyltransferase that synthesizes wax-esters. Planta. 2007;226(2):381-394.

56. Li F, Wu X, Lam P, et al. Identification of the wax ester synthase/ acyl-coenzyme A:diacylglycerol acyltransferase WSD1 required for stem wax ester biosynthesis in Arabidopsis. Plant Physiol. 2008;148(1): 97-107.

57. Turkish AR, Henneberry AL, Cromley D, et al. Identification of two novel human acyl-CoA wax alcohol acyltransferases: Members of the diacylglycerol acyltransferase 2 (DGAT2) gene superfamily. J Biol Chem. 2005;280(15):14755-14764.

58. Parish EJ, Terrence LB, Shengrong L. The chemistry of waxes and sterols. In: Akoh CC, Min DB, editors. Food Lipids: Chemistry, Nutrition, and Biochemistry. New York, NY; M. Dekker; 2002: 103-132.

59. Rehm BH, Steinbuchel A. Biochemical and genetic analysis of PHA synthases and other proteins required for PHA synthesis. Int $J$ Biol Macromol. 1999;25(1-3):3-19.

60. Chen GQ. A microbial polyhydroxyalkanoates (PHA) based bio- and materials industry. Chem Soc Rev. 2009;38(8):2434-2446. 
61. Somleva MN, Snell KD, Beaulieu JJ, Peoples OP, Garrison BR, Patterson NA. Production of polyhydroxybutyrate in switchgrass, a value-added co-product in an important lignocellulosic biomass crop. Plant Biotechnol J. 2008;6(7):663-678.

62. Suriyamongkol P, Weselake R, Narine S, Moloney M, Shah S. Biotechnological approaches for the production of polyhydroxyalkanoates in microorganisms and plants - a review. Biotechnol Adv. 2007;25(2): 148-175.

63. Kichise T, Taguchi S, Doi Y. Enhanced accumulation and changed monomer composition in polyhydroxyalkanoate (PHA) copolyester by in vitro evolution of Aeromonas caviae PHA synthase. Appl Environ Microbiol. 2002;68(5):2411-2419.

64. Taguchi S, Doi Y. Evolution of polyhydroxyalkanoate (PHA) production system by "enzyme evolution": Successful case studies of directed evolution. Macromol Biosci. 2004;4(3):146-156.

65. Nomura CT, Taguchi S. PHA synthase engineering toward superbiocatalysts for custom-made biopolymers. Appl Microbiol Biotechnol. 2007;73(5):969-979.

66. Coleman RA. Diacylglycerol acyltransferase and monoacylglycerol acyltransferase from liver and intestine. Methods Enzymol. 1992;209: 98-104.

67. Lung SC, Weselake RJ. Diacylglycerol acyltransferase: a key mediator of plant triacylglycerol synthesis. Lipids. 2006;41(12): 1073-1088.

68. Seethala R, Peterson T, Dong J, et al. A simple homogeneous scintillation proximity assay for acyl-coenzyme A: diacylglycerol acyltransferase. Anal Biochem. 2008;383(2):144-150.

69. Cook ND. Scintillation proximity assay: A versatile high-throughput screening technology. Drug Discov Today. 1996;1(7):287-294.

70. Zheng W, Carroll SS, Inglese J, Graves R, Howells L, Strulovici B. Miniaturization of a hepatitis $\mathrm{C}$ virus RNA polymerase assay using a -102 degrees $\mathrm{C}$ cooled CCD camera-based imaging system. Anal Biochem. 2001;290(2):214-220.

71. Nare B, Allocco JJ, Kuningas R, et al. Development of a scintillation proximity assay for histone deacetylase using a biotinylated peptide derived from histone-H4. Anal Biochem. 1999;267(2):390-396.

72. Ahsen O, Voigtmann U, Klotz M, et al. A miniaturized highthroughput screening assay for fucosyltransferase VII. Anal Biochem. 2008;372(1):96-105.

73. Zhang Y, Yang F, Kao YC, Kurilla MG, Pompliano DL, Dicker IB Homogenous assays for Escherichia coli DnaB-stimulated DnaG primase and DnaB helicase and their use in screening for chemical inhibitors. Anal Biochem. 2002;304(2):174-179.

74. Wu S, Liu B. Application of scintillation proximity assay in drug discovery. BioDrugs. 2005;19(6):383-392.

75. Maedler K, Oberholzer J, Bucher P, Spinas GA, Donath MY. Monounsaturated fatty acids prevent the deleterious effects of palmitate and high glucose on human pancreatic beta-cell turnover and function. Diabetes. 2003;52(3):726-733.

76. Steinberg D. Thematic review series: The pathogenesis of atherosclerosis. An interpretive history of the cholesterol controversy, part V: The discovery of the statins and the end of the controversy. $J$ Lipid Res. 2006;47(7):1339-1351.

77. Schaffer JE. Lipotoxicity: When tissues overeat. Curr Opin Lipidol. 2003;14(3):281-287.

78. Buszczak M, Lu X, Segraves WA, Chang TY, Cooley L. Mutations in the midway gene disrupt a Drosophila acyl coenzyme A:diacylglycerol acyltransferase. Genetics. 2002;160(4):1511-1518.

79. Listenberger LL, Han X, Lewis SE, et al. Triglyceride accumulation protects against fatty acid-induced lipotoxicity. Proc Natl Acad Sci U S A. 2003;100(6):3077-3082.

80. Liu L, Shi X, Bharadwaj KG, et al. DGAT1 expression increases heart triglyceride content but ameliorates lipotoxicity. J Biol Chem. 2009;284(52):36312-36323.

81. Sandager L, Gustavsson MH, Stahl U, et al. Storage lipid synthesis is non-essential in yeast. J Biol Chem. 2002;277(8):6478-6482.
82. Faergeman NJ, DiRusso CC, Elberger A, Knudsen J, Black PN. Disruption of the Saccharomyces cerevisiae homologue to the murine fatty acid transport protein impairs uptake and growth on long-chain fatty acids. J Biol Chem. 1997;272(13):8531-8538.

83. Faergeman NJ, Black PN, Zhao XD, Knudsen J, DiRusso CC. The acyl-CoA synthetases encoded within FAA1 and FAA4 in Saccharomyces cerevisiae function as components of the fatty acid transport system linking import, activation, and intracellular utilization. J Biol Chem. 2001;276(40):37051-37059.

84. Garbarino J, Padamsee M, Wilcox L, et al. Sterol and diacylglycerol acyltransferase deficiency triggers fatty acid-mediated cell death. J Biol Chem. 2009;284(45):30994-31005.

85. Petschnigg J, Wolinski H, Kolb D, et al. Good fat, essential cellular requirements for triacylglycerol synthesis to maintain membrane homeostasis in yeast. J Biol Chem. 2009;284(45):30981-30993.

86. Siloto RM, Truksa M, He X, McKeon T, Weselake RJ. Simple methods to detect triacylglycerol biosynthesis in a yeast-based recombinant system. Lipids. 2009;44(10):963-973.

87. Zhang Q, Chieu HK, Low CP, Zhang SC, Heng CK, Yang HY. Schizosaccharomyces pombe cells deficient in triacylglycerols synthesis undergo apoptosis upon entry into the stationary phase. $J$ Biol Chem. 2003;278(47):47145-47155.

88. Varadarajan N, Georgiou G, Iverson BL. An engineered protease that cleaves specifically after sulfated tyrosine. Angew Chem Int Ed Engl. 2008;47(41):7861-7863.

89. Varadarajan N, Rodriguez S, Hwang BY, Georgiou G, Iverson BL. Highly active and selective endopeptidases with programmed substrate specificities. Nat Chem Biol. 2008;4(5):290-294.

90. Nair NU, Zhao H. Evolution in reverse: Engineering a D-xylosespecific xylose reductase. Chembiochem. 2008;9(8):1213-1215.

91. Fasan R, Chen MM, Crook NC, Arnold FH. Engineered alkanehydroxylating cytochrome $\mathrm{P} 450$ (BM3) exhibiting native-like catalytic properties. Angew Chem Int Ed Engl. 2007;46(44):8414-8418.

92. Fasan R, Meharenna YT, Snow CD, Poulos TL, Arnold FH. Evolutionary history of a specialized p450 propane monooxygenase. $J \mathrm{Mol}$ Biol. 2008;383(5):1069-1080.

93. Greenspan P, Mayer EP, Fowler SD. Nile red - A selective fluorescent stain for intracellular lipid droplets. J Cell Biol. 1985;100(3): 965-973.

94. Diaz G, Melis M, Batetta B, Angius F, Falchi AM. Hydrophobic characterization of intracellular lipids in situ by Nile Red red/yellow emission ratio. Micron. 2008;39(7):819-824.

95. Gorenflo V, Steinbuchel A, Marose S, Rieseberg M, Scheper T. Quantification of bacterial polyhydroxyalkanoic acids by Nile red staining. Appl Microbiol Biotechnol. 1999;51(6):765-772.

96. Müller S, Lösche A, Bley T, Scheper T. A flow cytometric approach for characterization and differentiation of bacteria during microbial processes. Appl Microbiol Biotechnol. 1995;43(1):93-101.

97. Degelau A, Scheper T, Scheper T, Bailey JE, Guske C. Fluorometric measurement of poly- $\beta$ hydroxybutyrate in Alcaligenes eutrophus by flow cytometry and spectrofluorometry. Appl Microbiol Biotechnol. 1995;42(5):653-657.

98. James BW, Mauchline WS, Dennis PJ, Keevil CW, Wait R. Poly3-hydroxybutyrate in Legionella pneumophila, an energy source for survival in low-nutrient environments. Appl Environ Microbiol. 1999;65(2):822-827.

99. Vidal-Mas J, Resina P, Haba E, Comas J, Manresa A, VivesRego J. Rapid flow cytometry - Nile red assessment of PHA cellular content and heterogeneity in cultures of Pseudomonas aeruginosa $47 \mathrm{~T} 2$ (NCIB 40044) grown in waste frying oil. Antonie Van Leeuwenhoek. 2001;80(1):57-63.

100. Spiekermann P, Rehm BH, Kalscheuer R, Baumeister D, Steinbuchel A. A sensitive, viable-colony staining method using Nile red for direct screening of bacteria that accumulate polyhydroxyalkanoic acids and other lipid storage compounds. Arch Microbiol. 1999;171(2): $73-80$. 
101. Matsumoto K, Nagao R, Murata T, et al. Enhancement of poly (3-hydroxybutyrate-co-3-hydroxyvalerate) production in the transgenic Arabidopsis thaliana by the in vitro evolved highly active mutants of polyhydroxyalkanoate (PHA) synthase from Aeromonas caviae. Biomacromolecules. 2005;6(4):2126-2130.

102. Tyo KE, Zhou H, Stephanopoulos GN. High-throughput screen for poly-3-hydroxybutyrate in Escherichia coli and Synechocystis sp. strain PCC6803. Appl Environ Microbiol. 2006;72(5):3412-3417.

103. Tyo KE, Jin YS, Espinoza FA, Stephanopoulos G. Identification of gene disruptions for increased poly-3-hydroxybutyrate accumulation in Synechocystis PCC 6803. Biotechnol Prog. 2009;25(5):1236-1243.

104. de la Jara A, Mendonza H, Martel A, et al. Flow cytometric determination of lipid content in a marine dinoflagellate, Crypthecodinium cohnii. J Appl Phycol. 2003;15(5):433-438.
105. da Silva TL, Reis A, Medeiros R, Oliveira AC, Gouveia L. Oil production towards biofuel from autotrophic microalgae semicontinuous cultivations monitorized by flow cytometry. Appl Biochem Biotechnol. 2009;159(2):568-578.

106. Gao C, Xiong W, Zhang Y, Yuan W, Wu Q. Rapid quantitation of lipid in microalgae by time-domain nuclear magnetic resonance. J Microbiol Methods. 2008;75(3):437-440.

107. Jones KS, Alimov AP, Rilo HL, Jandacek RJ, Woollett LA, Penberthy WT. A high throughput live transparent animal bioassay to identify non-toxic small molecules or genes that regulate vertebrate fat metabolism for obesity drug development. Nutr Metab (Lond). 2008;5:23
International Journal of High Throughput Screening

\section{Publish your work in this journal}

International Journal of High Throughput Screening is an international, peer-reviewed, open access journal publishing original research, reports, editorials, reviews and commentaries dedicated to all aspects of high throughput screening, especially related to drug discovery and associated areas of biology and chemistry. The manuscript management sys-

\section{Dovepress}

tem is completely online and includes a very quick and fair peer-review system. Visit http://www.dovepress.com/testimonials.php to read real quotes from published authors.

\footnotetext{
Submit your manuscript here: http://www.dovepress.com/international-journal-of-high-throughput-screening-journal
} 